\title{
Hubungan Sikap Dan Kemampuan Kerjasama Terhadap Pembelajaran Online Menggunakan Pendekatan Tutor Teman Sebaya
}

\author{
Astina*, Noor Hujjatusnaini \\ Program Studi Tadris Biologi, Jurusan Pendidikan Matematika dan Ilmu Pengetahuan Alam, Fakultas \\ Tarbiyah dan Ilmu Keguruan, IAIN Palangkaraya, Palangkaraya, Kalimantan Tengah, Indonesia \\ Email :Astina662@gmail.com
}

\begin{abstract}
Abstrak
Penelitian ini bertujuan untuk mengetahui sikap mahasiswa dalam pembelajaran online dan mengetahui kemampuan kerjasama mahasiswa dalam pembelajaran online. Penelitian ini menggunakan pendekatan kuantitatif. Jenis penelitian menggunakan pendekatan deskriptif kuantitatif. Variabel yang akan dikaji yaitu sikap mahasiswa, kemampuan kerjasama dan hasil belajar. Data diambil melalui angket dan soal. Teknik analisis data terdiri atas tiga tahap, yaitu tahapan alisis skala likert, uji n-gain dan uji korelasi product moment. Uji hipotesi smenggunakan korelasi product moment dengan bantuan aplikasi SPSS 21. Hasil penelitian ini menunjukkan sikap terhadap hasil belajar kognitif mahasiswa berkorelasi positif dilambangkan dengan $\mathrm{r}$ hitung sebesar 0,534. Kemampuan kerjasama r hitung sebesar 0,417.
\end{abstract}

Kata kunci: Hasil Belajar, Kemampuan Kerjasama dan Sikap

\begin{abstract}
This study aims to determine student attitudes in online learning and to determine the ability of student collaboration in online learning. This study uses a quantitative approach. This type of research uses a quantitative descriptive approach. The variables to be studied are student attitudes, collaboration skills and learning outcomes. The data were collected through questionnaires and questions. The data analysis technique consists of three stages, namely the Likert scale analysis stage, the N-Gain test and the product moment correlation test. Hypothesis testing uses the product moment correlation with the help of the SPSS 21 application. The results of this study indicate that attitudes towards student cognitive learning outcomes are positively correlated, represented by $\mathrm{r}$ count of 0.534 . The skills of collaboration $\mathrm{r}$ count is 0.417 .
\end{abstract}

Keywords: Attitudes, collaboration skills and Learning Outcomes

\section{PENDAHULUAN}

Pendidikan adalah usaha yang sadar, teratur dan sistematis dalam memberikan bimbingan orang lain yang sedang memulai proses menuju kedewasaan. Pendidikan adalah sektor penting untuk menciptakan kecerdasan, akhlak mulia dan keterampilan, dengan tujuan untuk dapat mengembangkan potensi yang ada pada diri. Pendidikan selalu menuntut adanya perbaikan, karena Pendidikan bersifat dinamis bukan statis, sehingga harus selalu ada perbaikan dan perubahan secara terus menerus.
Pendidikan bukan hanya sekedar tentang upaya mencerdaskan mahasiswa saja, tetapi juga membentuk karakter mahasiswa.

Karakter yang terbentuk pada mahasiswa berkorelasi terhadap keterampilan, baik keterampilan berkomunikasi sesame teman, keterampilan menggunakan teknologi dan keterampilan lainnya yang dapat menunjang dalam proses pembelajaran. Pembelajaran di era revolusi 4.0 memiliki tujuan utama dalam menanamkan pendidikan karakter yang kuat pada mahasiswa. Karakter 
yang diharapkan tercermin dalam sikap dan kemampuan saling bekerjasama antar individu. Kurangnya kemampuan mahasiswa dalam komunikasi dan bekerjasama merupakan permasalahan penting yang dapat mengganggu proses pembelajaran (Maasawet, 2011).

Mata kuliah biologi sel merupakan mata kuliah yang menuntut pemahaman yang tinggi, sehingga diperlukan sikap saling bekerjasama antar mahasiswa, dengan harapan dapat mempermudah dalam memahami materi perkuliahan. Biologi sel tidak hanya sekedar mengetahui materi saja, tetapi juga harus memahami konsep. Oleh karena itu sikap yang baik dalam pembelajaran dapat membantu mahasiswa dalam memahami konsep materi lebih baik.

Perkuliahan matakuliah biologi sel menunjukkan sikap mahasiswa belum seperti yang diharapkan. Kurangnya kemandirian dan sikap saling bekerjasama mahasiswa dalam proses pembelajaran. Mahasiswa lebih cenderung diam, tidak berani bertanya, serta tidak berani untuk mengeluarkan pendapat, sehingga interaksi menjadi kurang baik antara dosen dan mahasiswa maupun antar sesame mahasiswa. Untuk menciptakan pembelajaran yang menyenangkan dan memungkinkan mahasiswa terlibat secara langsung dalam proses pembelajaran, diperlukan analisis model pembelajaran yang tepat dalam menyampaikan materi tertentu.

Model pembelajaran yang tepat akan mampu menciptakan pembelajaran yang menyenangkan, keterlibatan mahasiswa menjadi lebih aktif dalam pembelajaran, dan akan mempermudah transfer informasi.
Informasi dan pengetahuan yang dimiliki mahasiswa berkorelasi terhadap sikap dan perilaku mahasiswa. Pengetahuan dapat dikatakan sebagai fakta yang lebih dianggap sebagai proses pembentukan informasi yang terus berkembang dan berubah-ubah, sedangkan sikap merupakan implementatif dari pengetahuan yang bias diperoleh melalui interaksi antar individu dalam pembelajaran. Interaksi tersebut dapat terjadi secara langsung maupun secara tidak langsung, seperti di rumah, sekolah, ataupun tempat lainnya (Anwar, 2009).

Interaksi dan keterlibatan aktif mahasiswa dalam pembelajaran akan mempermudah pencapaian tujuan pembelajaran dapat dicapai optimal dengan menggunakan metode pendekatan yang tepat. Berdasarkan hasil observasi di IAIN Palangka Raya fakultas MIPA Program Studi Tadris Biologi semester VI bahwa mahasiswa mengalami kesulitan dalam memahami materi biologisel, sehingga dosen dituntut ekstra dalam memberikan penegasan materi. Biologi sel merupakan mata kuliah yang wajib ditempuh oleh mahasiswa program studi pendidikan biologi yang diberikan pada mahasiswa semester IV dengan bobot 2 SKS yang berlangsung selama 16 kali pertemuan. Biologi sel merupakan mata kuliah yang cenderung dianggap sulit oleh mahasiswa.

Kebanyakan mahasiswa masih sulit memahami materi biologi sel terutama materi siklus sel. Materi siklus sel merupakan materi yang menuntut pemahaman yang lebih mendalam, sehingga sangat memerlukan serangkaian strategi atau pendekatan 
pembelajaran yang tepat, dengan harapan mahasiswa lebih mudah dalam memahami materi tersebut. Pembelajaran mata kuliah biologi sel khususnya untuk materi siklus sel dengan system pembelajaran dalam kondisi pandemi Covid-19 memiliki kesulitan tersendiri dalam mencapai tujuan pembelajaran.

Untuk dapat mencapai tujuan pembelajaran online dengan lebih baik, dosen dituntut untuk mampu memilih model pembelajaran yang tepat sesuai dengan keadaan sekarang salah satunya adalah menggunakan pendekatan tutor teman sebaya. Pendekatan tutor teman sebaya adalah pendekatan yang dapat membantu mahasiswa agar lebih mudah memahami dalam pembelajaran (Falah, 2014).

Pembelajaran dengan tutor sebaya dapat membantu rekan sebaya dalam aspek akademis, emosi, dan disiplin. Bantuan tutor sebaya membuat pembelajaran akan lebih efektif, komunikatif dan efisien. (Indriani dkk, 2016). Konsepteoritik yang berlandaskan pada penelitian sebelumnya yang dijabarkan di atas mendasari pelaksanaan penelitian ini dengan judul "Hubungan Sikap dan Kemampuan Kerjasama Terhadap Pembelajaran Online Menggunakan Pendekatan Tutor Teman Sebaya Pada Materi Siklus Sel Mata Kuliah Biologi Sel di IAIN Palangka Raya.

\section{METODE PENELITIAN}

Penelitian ini dilaksanakan di Institut Agama Islam Negeri (IAIN) Palangka Raya. Dalam penelitian ini peneliti sebagai observer riset. Data primer dalam penelitian ini adalah data-data yang diperoleh secara langsung dari subjek penelitian, yaitu dari mahasiswa Prodi Tadris Biologi semester IV, baik yang bertugas sebagai tutor sebay amaupun yang tidak. Dalam penelitian ini peneliti mengamati pengajar dengan menggunakan model tutor teman sebaya.

Selain memperoleh data dengan wawancara hasil penelitian juga diperoleh dengan menggunakan angket yang sudah diisi mahasiswa melalui google form. Dalam penelitian ini mengambil materi siklus sel yang bertujuan untuk mengetahui bagaimana sikap dan kemampuan kerjasama mahasiswa serta hasil belajar mahasiswa dalam menggunakan pendekatan tutor teman sebaya.

Instrumen yang digunakan dalam penelitian ini adalah : 1) Angket sikap mahasiswa 2) Angket kemampuan kerjasama mahasiswa, dan 3) Tes tertulis berupa tes hasil belajar kognitif yaitu tes awal dan tes akhir (pretest-posttest). Data yang diperoleh bersifat kuantitatif berupa skor sikap mahasiswa terhadap pembelajaran online menggunakan tutor teman sebaya, skor angket kemampuan kerjasama dan skor hasil belajar kognitif mahasiswa dalam pembelajaran online pada materi siklus sel.

Teknik analisis data menggunakan analisis skala Likert, Uji statistic korelasi product moment serta uji N-Gain.

\section{HASIL DAN PEMBAHASAN}

Hasil penelitian menunjukkan bahwa penskoran pada lembar angket sikap dan 
kemampuan kerjasama dinyatakan dalam skala Likert yaitu 1 (sangat tidak setuju), 2 (tidak setuju), 3 (setuju) dan 4 (sangat setuju). Data yang diperoleh dari hasil pengisian angket yang telah diberikan kepada mahasiswa setelah pembelajaran. Angket yang diberikan terdiri atas 7 indikator sikap yang terdapat 45 pernyataan dengan empat pilihan jawaban.

Adapun persentase sikap mahasiswa pada pembelajaran online menggunakan pendekatan tutor teman sebaya yaitu diketahui bahwa sebesar $93,93 \%$ sikap mahasiswa memiliki sikap dalam kategori "cukup", dan 6,06\% mahasiswa termasuk kedalam kategori “tinggi”. Persentase sikap mahasiswa dengan menggunakan pendekatan tutor teman sebaya pada pembelajaran online menunjukkan perbandingan skor berdasarkan indikator sebagaimana tampak pada Gambar 1 berikut:

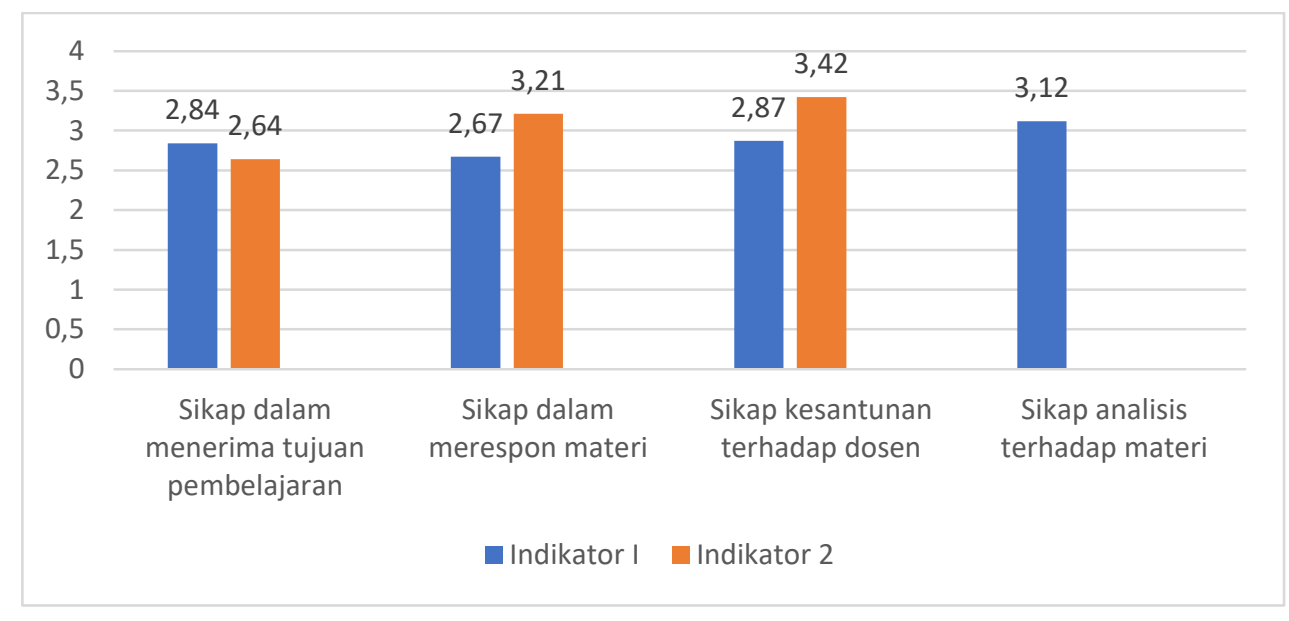

Gambar 1. Perbandingan skor indikator sikap

Berdasarkan Gambar di atas, variabel sikap kesantunan terhadap dosen dengan indicator interaksi pendidik dengan mahasiswa dalam merespon materi pembelajaran dengan menggunakan pendekatan tutor teman sebaya lebih tinggi dibandingkan dengan indicator lainnya.

Adapun persentase kemampuan kerjasama mahasiswa pada pembelajaran online menggunakan pendekatan tutor teman sebaya maka diperoleh data persentase. Persentase dari 33 mahasiswa yang diteliti yaitu terdapat persentase $21,21 \%$ dengan jumlah 7 orang mahasiswa termasuk dalam kriteria "tinggi" dan 78,78\% dengan jumlah mahasiswa 26 orang termasuk dalam kriteria “cukup". Kriteria rendah dan kurang tidak ada yaitu persentasenya sama dengan nol. Untuk 33 mahasiswa yaitu terdapat 7 mahasiswa termasuk dalam kriteria tinggi dan 26 mahasiswa dalam kriteria tinggi.

Persentase kemampuan kerjasama mahasiswa dengan menggunakan pendekatan tutor teman sebaya pada pembelajaran online 
indikator sebagaimana tampak pada Gambar 2

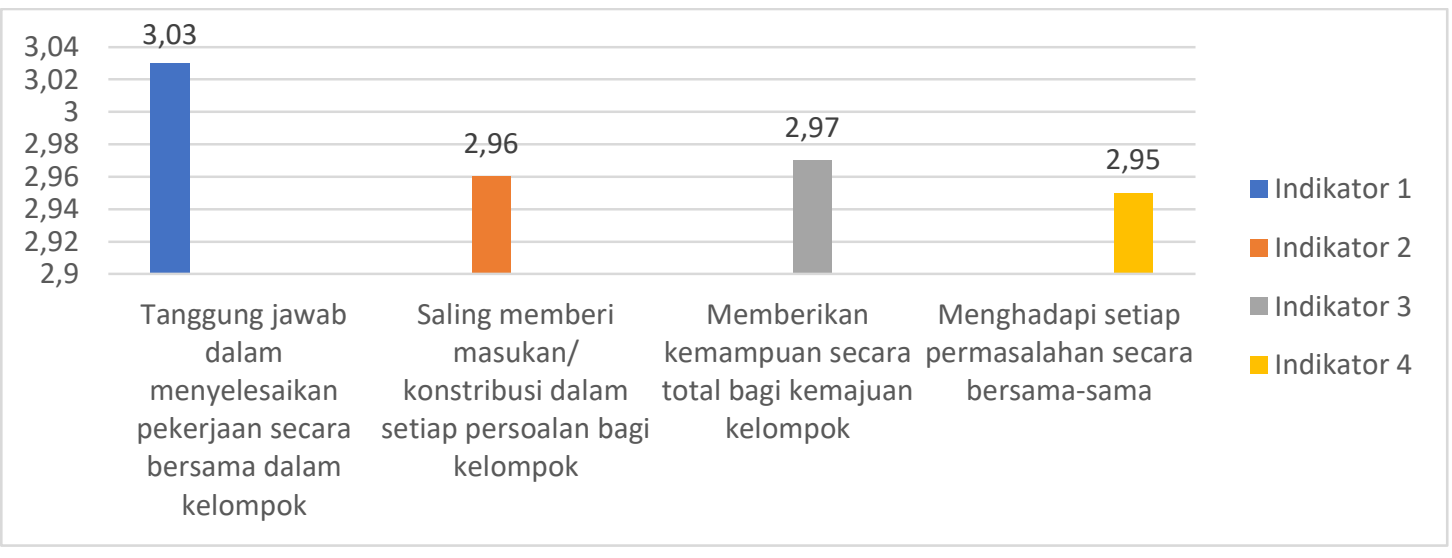

Gambar 2. Perbandingan skor kemampuan kerjasama

Berdasarkan Gambar di atas, indicator tanggungjawab dalam menyelesaikan pekerjaan secara bersama dalam kelompok, dengan menggunakan pendekatan tutor teman sebaya lebih tinggi dengan rata-rata 3,03 dibandingkan dengan indikator yang lainnya.

Data hasil belajar kognitif yang didapatkan dari hasil pembelajaran menggunakan pendekatan tutor teman sebaya dan menganalisis hasil yang didapat dari tes awal (pretest) dan tesakhir (posttest). Tes hasil belajar ini tujuannya adalah untuk mengetahui ketuntasan belajar mahasiswa setelah belajar menggunakan pendekatan tutor teman sebaya. Analisis ini menggunakan ketuntasan minimum yang sudah ditetapkan yaitu nilai ketuntasan minimum untuk mata kuliah biologi sel adalah 60 .
Instrument yang digunakan dalam penelitian ini untuk mengetahui ketuntasan hasil belajar mahasiswa adalah instrument soal pilihan ganda sebanyak 25 soal dengan 5 pilihan jawaban yaitu A, B, C, D dan E. Soal tersebut disajikan dalam bentuk google form sehingga dapat memudahkan mahasiswa dalam memilih dan mengisi soal. Data hasil belajar kognitif dapat dilihat pada Tabel 1 berikut: 
Tabel 1. Hasil Belajar Kognitif

\begin{tabular}{|c|c|c|c|c|}
\hline KodeMahasiswa & Pretest & Ketuntasan & Posttest & Ketuntasan \\
\hline $\mathrm{RQ}$ & 48 & TidakTuntas & 80 & Tuntas \\
\hline SNA & 52 & TidakTuntas & 80 & Tuntas \\
\hline SNL & 36 & TidakTuntas & 76 & Tuntas \\
\hline LIA & 44 & TidakTuntas & 72 & Tuntas \\
\hline $\mathrm{N}$ & 60 & Tuntas & 80 & Tuntas \\
\hline $\mathrm{NI}$ & 56 & TidakTuntas & 84 & Tuntas \\
\hline $\mathrm{AM}$ & 20 & TidakTuntas & 76 & Tuntas \\
\hline MIP & 52 & TidakTuntas & 72 & Tuntas \\
\hline $\mathrm{Y}$ & 60 & Tuntas & 76 & Tuntas \\
\hline RS & 60 & Tuntas & 80 & Tuntas \\
\hline $\mathrm{RC}$ & 28 & TidakTuntas & 72 & Tuntas \\
\hline $\mathrm{AZ}$ & 44 & TidakTuntas & 56 & TidakTuntas \\
\hline $\mathrm{NR}$ & 16 & TidakTuntas & 76 & Tuntas \\
\hline $\mathrm{SZ}$ & 36 & TidakTuntas & 76 & Tuntas \\
\hline SW & 4 & TidakTuntas & 80 & Tuntas \\
\hline I & 40 & TidakTuntas & 72 & Tuntas \\
\hline $\mathrm{F}$ & 40 & TidakTuntas & 76 & Tuntas \\
\hline $\mathrm{MO}$ & 48 & TidakTuntas & 80 & Tuntas \\
\hline ASW & 20 & TidakTuntas & 76 & Tuntas \\
\hline PAPA & 36 & TidakTuntas & 80 & Tuntas \\
\hline $\mathrm{YF}$ & 48 & TidakTuntas & 76 & Tuntas \\
\hline NYS & 16 & TidakTuntas & 72 & Tuntas \\
\hline IA & 16 & TidakTuntas & 76 & Tuntas \\
\hline NSW & 16 & TidakTuntas & 76 & Tuntas \\
\hline MM & 32 & TidakTuntas & 76 & Tuntas \\
\hline MI & 44 & TidakTuntas & 72 & Tuntas \\
\hline MTA & 40 & TidakTuntas & 72 & Tuntas \\
\hline RH & 20 & TidakTuntas & 72 & Tuntas \\
\hline$M$ & 24 & TidakTuntas & 72 & Tuntas \\
\hline IY & 20 & TidakTuntas & 72 & Tuntas \\
\hline LNH & 36 & TidakTuntas & 72 & Tuntas \\
\hline $\mathrm{AP}$ & 28 & TidakTuntas & 76 & Tuntas \\
\hline DW & 20 & TidakTuntas & 76 & Tuntas \\
\hline
\end{tabular}

Berdasarkan tes hasil belajar pada tabel di atas dapat dilihat bahwa dari rata-rata semua mahasiswa untuk hasil pretestnya adalah 35.15 yang mana hanya terdapat 3 mahasiswa yang tuntas sedangkan 30 mahasiswa lainnya masuk kategori tidak tuntas. Sedangkan hasil belajar mahasiswa pada posttest rata-rata nilai keseluruhan mahasiswa yaitu 75.15 atau 32 mahasiswa tuntas dan 1 mahasiswa yang tidak tuntas. Ini berarti bahwa terjadinya peningkatan terhadap proses pembelajaran yang dapat dibuktikan 
dengan hasil belajar pretest dan posttest mahasiswa yang meningkat ketuntasan nilai mahasiswanya.

Data nilai sikap mahasiswa sebagai variabel X1 dan Y sebagai pembelajaran online menggunakan pendekatan tutor teman sebaya yang di teliti dengan menggunakan hasil belajar mahasiswa untuk mengetahui efektifitas dalam pembelajarannya. Untuk mengetahui korelasi antara variabel $\mathrm{X}$ dan variabel $Y$ peneliti menggunakan bantuan aplikasi SPSS 21 untuk lebih jelasnya dapat dilihat pada Tabel 2 berikut:

Tabel 2. Korelasi antara Variabel X dan Y

\section{Correlations}

\begin{tabular}{llrr}
\hline & & \multicolumn{1}{c}{ Sikap } & Hasil belajar \\
\hline \multirow{3}{*}{ Sikap } & \multicolumn{1}{l}{ Pearson Correlation } & 1 & $.534^{* * *}$ \\
\cline { 2 - 4 } & Sig. (2-tailed) & & .001 \\
\cline { 2 - 4 } & $\mathrm{N}$ & 33 & 33 \\
\hline \multirow{3}{*}{ Hasil belajar } & Pearson Correlation & $.534^{* *}$ & 1 \\
\cline { 2 - 4 } & Sig. (2-tailed) & .001 & 33 \\
\cline { 2 - 4 } & $\mathrm{N}$ & 33 & \\
\hline
\end{tabular}

**. Correlation is significant at the 0.01 level (2-tailed).

kecil dari $\mathrm{r}$ table maka hipotesis $\left(\mathrm{H}_{0}\right)$

Berdasarkan perhitungan di atas, diperoleh nilai koefisien korelasi antara variabel X1 dan Y sebesar +0,534 dengan signifikansi 0,001. Berdasarkan hasil data nilai korelasi sikap dan hasil belajar mahasiswa adalah $+0,534$. Nilai $r$ hitung tersebut akan di bandingkan dengan nilainilai $r$ tabel.

Ketentuan dalam pengujian hipotesis adalah jika $r$ hitung lebih besar dari $r$ tabel maka hipotesis $\left(\mathrm{H}_{\mathrm{a}}\right)$ diterima dan hipotesis $\left(\mathrm{H}_{0}\right)$ ditolak. Sebaliknya jika $\mathrm{r}$ hitung lebih diterima dan hipotesis $\left(\mathrm{H}_{\mathrm{a}}\right)$ ditolak.

Data nilai kemampuan kerjasama mahasiswa sebagai variabel X2 dan nilai hasil belajar dari pembelajaran online menggunakan tutor teman sebaya sebagai variabel Y. Untuk mengetahui adanya korelasi antara variabel $\mathrm{X} 2$ dan variabel $\mathrm{Y}$ peneliti menggunakan bantuan aplikasi SPSS 21 agar lebih jelasnya tersusun pada Tabel 3 sebagai berikut:

Tabel 3. Korelasi antara variabel X2 dan Y

\begin{tabular}{|c|c|c|c|}
\hline & & $\begin{array}{l}\text { KemampuanKerja } \\
\text { sama }\end{array}$ & Hasil Belajar \\
\hline \multirow{3}{*}{ KemampuanKerjasama } & Pearson Correlation & 1 & $.417^{*}$ \\
\hline & Sig. (2-tailed) & & .016 \\
\hline & $\mathrm{N}$ & 33 & 33 \\
\hline \multirow{3}{*}{ Hasil Belajar } & Pearson Correlation & $.417^{*}$ & 1 \\
\hline & Sig. (2-tailed) & .016 & \\
\hline & $\mathrm{N}$ & 33 & 33 \\
\hline
\end{tabular}


Berdasarkan perhitungan di atas, diperoleh nilai koefisien korelasi antara variabel $\mathrm{X} 2$ dan $\mathrm{Y}$ sebesar $+0,417$ dengan signifikansi 0,016. Berdasarkan hasil data nilai korelasi sikap dan hasil belajar mahasiswa adalah $+0,417$. Nilai $r$ hitung tersebut akan di bandingkan dengan nilai-nilai $r$ tabel. Ketentuan dalam pengujian hipotesis adalah jika $r$ hitung lebih besar dari $r$ table maka hipotesis $\left(\mathrm{H}_{\mathrm{a}}\right)$ diterima dan hipotesis $\left(\mathrm{H}_{0}\right)$ ditolak. Sebaliknya jika $r$ hitung lebih kecil dari $\mathrm{r}$ table maka hipotesis $\left(\mathrm{H}_{0}\right)$ diterima dan hipotesis $\left(\mathrm{H}_{\mathrm{a}}\right)$ ditolak.

Tabel 4. Korelasi Antara Sikap, Kerjasama, dan Hasil Belajar

Model Summary

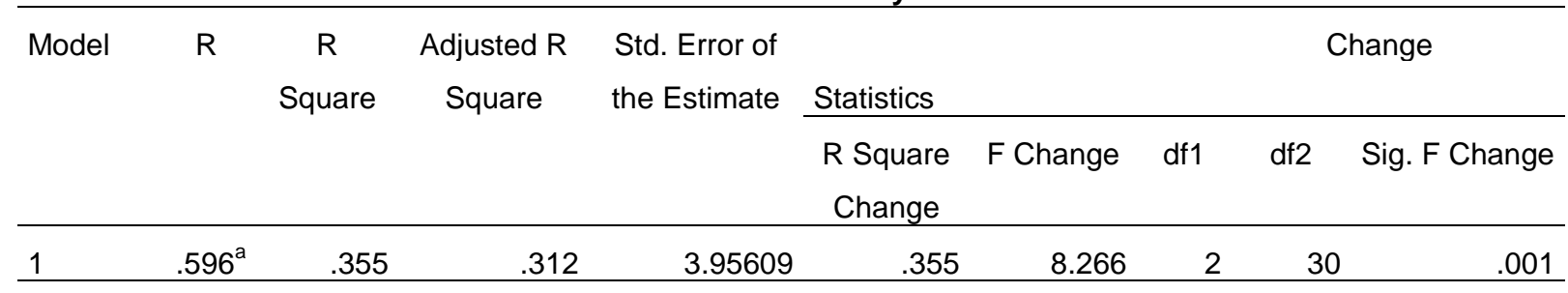

a. Predictors: (Constant), KemampuanKerjasama, Sikap

Berdasarkan perhitungan

menggunakan aplikasi SPSS 21 dipeoleh nilai

koefisien korelasi sebesar 0,596 dengansignifikasi 0,001. Nilai $r$ hitung tersebut akan dibandingkan pada nilai-nilai $r$ tabel. Ketentuan dalam pengujian hipotesis adalah jika $\mathrm{r}$ hitung lebih besar dari $\mathrm{r}$ table maka hipotesis $\left(\mathrm{H}_{\mathrm{a}}\right)$ diterima dan hipotesis $\left(\mathrm{H}_{0}\right)$ ditolak. Sebaliknya jika $r$ hitung lebih kecil dari $\mathrm{r}$ table maka hipotesis $\left(\mathrm{H}_{0}\right)$ diterima dan hipotesis $\left(\mathrm{H}_{\mathrm{a}}\right)$ ditolak.

\section{SIMPULAN}

Berdasarkan hasil pembahasan di atas maka dapat disimpulkan sikap mahasiswa
Data hasil analisis nilai sikap (X1), kemampuan kerjasama (X2) dan hasil belajar (Y) dengan menggunakan pendekatan tutor teman sebaya, untuk mengetahui korelasi antara sikap, kemampuan kerjasama dan hasil belajar peneliti menggunakan aplikasi SPSS 21 untuk lebih jelasnya dapat dilihat pada Tabel 4 berikut:

terhadap pembelajaran online diperoleh
persentase sebesar 93,93\% atau di kategorikan cukup, dan sebesar $6.06 \%$ mahasiswa termasuk dalam kategori tinggi. Kemampuan kerjasama terhadap pembelajaran online diperoleh persentase sebesar $78,78 \%$ atau di kategori cukup, dan sebesar 21,21\% mahasiswa termasuk kategori tinggi. dan kemampuan kerjasama terhadap hasil belajar mahasiswa berkorelasi positif baik secara parsial maupun secar simultan. Sikap terhadap hasil belajar kognitif mahasiswa berkorelasi positif di lambangkan dengan $\mathrm{r}$ hitung sebesar 0,534. Kemampuan kerjasama $\mathrm{r}$ hitung sebesar 0,417. Hubungan antara sikap dan kemampuan kerjasama mahasiswa terhadap hasil belajar 
online berkorelasi secara simultan dengan korelasi sebesar 0,001 .

\section{DAFTAR PUSTAKA}

Anwar, H. 2009. Penilaian sikap llmiah dalam pembelajaran sains. Jurnal Pelangi Ilmu. 2(3): 103-114.

Falah IF. 2014. Model Pembelajaran Tutorial Sebaya: Telaah Teoritik. Jurnal Pendidikan Agama Islam-Ta'lim, 12(2): 175-186.

Indriani AM, Fina, Siti M. 2016. Metode Pembelajaran Tutor Sebaya Sebagai Upaya Meningkatkan Hasil Belajar Siswa. Journal of Accounting and Business Education, 2(2): 1-12
Maasawet, ET. 2011. Meningkatkan Kemampuan Kerjasama Belajar Biologi Melalui Penerapan Strategi Inkuiri Terbimbing Pada Siswa Kelas VII Smp Negeri VI Kota Samarinda Tahun Pelajaran 2010/2011 BIOEDUKASI, 2(1): 1-13. 